\title{
TAKAMINE AND SAHA: CONTACTS WITH WESTERN ASTROPHYSICS
}

\author{
DAVID H. DEVORKIN \\ Smithsonian Institution
}

In the fall of 1920 two young scholars happened to meet in London and found they had many interests in common in laboratory spectroscopy and astrophysics. One was an Indian and the other a Japanese, and their paths crossed as they visited American and European centers to learn the tools and techniques of the quantum theory. The young Japanese scholar, T. Takamine, whose home base was then the Institute of Physical and Chemical Research in Tokyo, was delighted to have met Meghnad Saha, from Calcutta, who was just putting the finishing touches on his fourth paper on ionization equilibrium in the atmospheres of the sun and stars. When they met, Takamine and Saha spoke of Sommerfeld's theories, and pledged to keep in touch. Thus began a correspondence that lasted for some twenty years, as Takamine returned to Japan from his long visits to American and European observatories and spectroscopic laboratories, and Saha returned to India. Of the two, Takamine had stayed the longer time in the West, mainly at Mount Wilson where he was in residence through much of 1919 working with John Anderson and A. S. King, and published on the "The Stark Effect for Metals." Takamine also returned to Mount Wilson in 1924 , and toured many spectroscopic laboratories in the United States continuing to hone his interests and technique. Elsewhere I have examined Saha's contacts with western astrophysics. Here I examine briefly how Takamine established and maintained contacts in the West and why he did so.

In the 1920s, in the wake of the Great War, the United States and England became the most desired places to visit for young physicists from the Far East interested in laboratory spectroscopy and astrophysics. Germany was still a draw, of course, as it had been the mecca for Japanese physicists for decades, not only for its prowess in physics, as James Bartholomew has pointed out in his study "The Formation of Science in Japan," but because the organization of its institutions allowed Japanese students to travel from place to place and not be confined to only one.[1] Because of the new impetus given to experimental spectroscopy after the war by advances in quantum physics, the better funded laboratories in the United States and Britain, and the fact that all three were allies during the war, made them more desirable places to spend research time.

Takamine's tours of the West were solely for personal research. In 1918, about to move from Kyoto to the new Institute for Physical Research in Tokyo, Takamine was given an extended leave of absence to work overseas. He toured spectroscopic laboratories and spent some eight months at George Ellery Hale's Mount Wilson Solar Observatory, where he worked in the Pasadena laboratories of J. A. Anderson and A. S. King on the Stark Effect for metals. Takamine arrived in Pasadena in September 1918 and took immediate benefit of the world-renown experimental facility, especially Anderson's large vacuum grating spectrograph.

Takamine also worked in T. R. Merton's Oxford Laboratory, and this is when he met Saha on a sojourn to London to examine spectroscopic equipment at Adam Hilger. Takamine returned to Tokyo to build his laboratory at the Institute of Physical and Chemical Research, a new form of research engine created in 1917 based upon the western concept of a national laboratory. Itakuru Kiyonobu and Yagi Eri have described the founding of this new Institute as a "major turning point in the history of Japanese science."[2] But even though Takamine, under Nagaoka, was able to establish a new spectroscopic laboratory at the Institute, he soon turned westward again as soon as the opportunity presented itself. 
An Imperial Prize allowed him return to Europe and America in 1924-1926, which he split between Bohr's Institute and Pasadena. His chief goal was to examine the newest improvements in laboratory technique. Takamine made two more trips to Pasadena in following years; one in 1930, where he worked on Balmer absorption spectra trying to reproduce stellar spectra, and his last in 1940, where he worked with a student, Tanaka, on EUV photo-ionization processes. He always marveled at the great industry of the Mount Wilson and Caltech spectroscopists. Beyond the laboratories themselves and great electric furnaces and vacuum spectrographs, there were well equipped instrument shops and a magnificent library. He never expressed any outward concern that his own facilities, or those in Japan generally, were not competitive. His only desire seemed was to be left to perform his own research, and to spend as much time as possible at the great laboratories in the West.

Takamine expressed his concerns in a series of letters to Saha in the late 1930s. It was not over the lack of equipment, or the lack of a robust infrastructure, but over the fate of pure science in Japan as the nation was coming more and more under the control of the military and his Institute was devoting the majority of its talent to applied research and war production, with the exception of nuclear physics. Takamine was not political and harbored unstated tensions that, in late 1938 at least, aggravated his already failing health. He admitted to Saha at one point that because he "suffered from a rather serious nervous over-strain" he had to stay away from large gatherings of scientists, work on committees, or confrontations of any kind.[3] Such feelings became more apparent in 1939, as the military exerted greater influence. Thus when Saha complained to Takamine of the pitiful conditions in India for experimental research, as well as the burdons of administration brought on by his political activities, Takamine revealed his own priorities and his own frustrations with the structure of science in both their countries: "I think that the ideal atmosphere of a civilized country ought to be that when a scientist does good work, he should get more \& more facilities \& leisure to push on his own research. But, evidently, the ideal conditions seems to be very far off!" [4]

Freedom to do research was the key for Takamine's continuing desire to work in the West. In 1938 he again obtained Carnegie funding, and this time brought an assistant, Yoshio Tanaka, to perform experimental work on the problem of the source of photoionization in the ionosphere, which Saha and others believed was to be found in the extreme ultraviolet. This required very special equipment. Takamine constructed a compact grazing incidence vacuum spectrograph at home, and he and Tanaka brought it to Anderson's laboratory in Pasadena to use the intense light sources that Anderson was world-famous for producing.

Takamine was always enraptured by the West. There he found not only the freedom for research, but inspiration as well. That he also sought out Saha's advice on occasion, and in the late 1930s based his own research on some of Saha's suggestions, reveals that it was not only his fascination with the West, but his search for physical insight, that propelled him to travel as often as he did. This seems to be much in keeping with Japanese scientists generally, and of Japanese culture, which, Bartholomew and others have claimed, had a tradition of "self-conscious borrowing" in the late 19th and early 20th centuries.[5] Thus in following the course of Takamine's scientific life, we have touched upon deeper motivations that propel quieter intellectuals toward their muse. Some chose the intellectual life for power and prestige, others, like Takamine, chose it for itself, but sought external influences for inspiration.

\section{References}

1. Bartholomew, James R. The Formation of Science in Japan. (Yale, 1989), 72.

2. Itakuru Kiyonobu and Yagi Eri, "The Japanese Research System and the Establishment of the Institute of Physical and Chemical Research," 158-207 in Sigeru Nakayama, David Swain and Yagi Eri, eds., Science and Society in Modern Japan. (MIT, 1974). [Originally published in 1957], p. 158

3. Letter, Takamine to Saha, September 6, 1938. Saha Institute for Nuclear Physics Archive (SINP).

4. Letter, Takamine to Saha, August 12, 1939. SINP.

5. Bartholomew, p. 83 . 